\title{
Exigências de proteína bruta e energia metabolizável em codornas de corte durante a fase de crescimento
}

[Protein and metabolizable energy requirements for meat type quail during the growing phase]

\author{
G.S.S. Corrêa $a^{1,5}$, M.A. Silva ${ }^{2,5}$, A.B. Corrê $a^{1}$, V. Almeida ${ }^{1}$, D.O. Fontes ${ }^{2,5}$, R.A. Torres ${ }^{3,5}$ \\ N.J.L. Dionello ${ }^{4,5}$ \\ ${ }^{1}$ Aluno de pós-graduação - EV-UFMG - Belo Horizonte, MG \\ ${ }^{2}$ Escola de Veterinária - UFMG \\ Caixa Postal 567 \\ 30123-970 - Belo Horizonte, MG \\ ${ }^{3}$ Departamento de Zootecnia - UFV - Viçosa, MG \\ ${ }^{4}$ Faculdade de Agronomia Eliseu Maciel - UFPel - Pelotas, RS \\ ${ }^{5}$ Bolsista do CNPq
}

\begin{abstract}
RESUMO
Estudou-se a exigência de proteína bruta e energia metabolizável para codornas européias em crescimento, em cinco períodos experimentais, de sete dias cada. Foram utilizadas 384 codornas de ambos os sexos, com sete dias de idade em delineamento experimental utilizado inteiramente ao acaso, em esquema fatorial de $2 \times 4$, dois níveis de energia (2900 e 3100kcal de EM/kg de ração) e quatro níveis de proteína $(22,24,26$ e $28 \%$ de PB), com seis repetições de oito animais cada. Foram estudadas as variáveis ganho de peso $(\mathrm{g})$, peso acumulado $(\mathrm{g})$, consumo de ração $(\mathrm{g})$ e conversão alimentar (g de ração/g de peso). Observou-se efeito linear dos níveis de proteína no primeiro período e quadrático nos demais períodos sobre o ganho de peso das aves. Os níveis de proteína foram estimados em $28,0 \%$ (2900kcal de EM/kg), 25,7\% (3100kcal de EM/kg), 27,9\%, 24,8\% (3100kcal de EM/kg) e 23,1\% $(2900 \mathrm{kcal}$ de $\mathrm{EM} / \mathrm{kg}$ ) para o segundo, terceiro, quarto e quinto período, respectivamente.
\end{abstract}

Palavras-chave: codorna de corte, energia metabolizável, proteína bruta

\begin{abstract}
Crude protein (CP) and metabolizable energy (ME) levels during five experimental periods of seven days each of the growing phase for European quail were determined. A total of 384 quails of both sexes were used in a completely randomized design in a $2 \times 4$ (energy and crude protein) factorial treatment with six replications of eight quails each. The metabolizable energy levels were 2900 and $3000 \mathrm{kcal}$ of $\mathrm{ME} / \mathrm{kg}$ of diet and the crude protein levels were 22, 24, 26 and 28\%. The analyzed variables were weight gain (g), accumulated weight (g), feed consumption (g), feed:gain ratio (g/g). Performance responses were evaluated by linear and quadratic regression of the traits on crude protein levels. Higher weight gains from the following protein and metabolizable energy levels combinations: $28.0 \%$ PB and $2900 \mathrm{kcal}$ $\mathrm{EM} / \mathrm{kg}$ (first period); $25.7 \% \mathrm{CP}$ and $3100 \mathrm{kcal} \mathrm{ME} / \mathrm{kg}$ (second period); $27.9 \%$ and $2900 \mathrm{kcal} \mathrm{ME} / \mathrm{kg}$ (third period); $24.8 \% \mathrm{~PB}$ and $3100 \mathrm{kcal} / \mathrm{kg}$ (fourth period) and $23.1 \% \mathrm{CP}$ and $2900 \mathrm{kcal} / \mathrm{kg}$ (fifth period).
\end{abstract}

Keywords: quail, nutritional requirement, metabolizable energy, crude protein

Recebido em 24 de outubro de 2005

Aceito em 2 de fevereiro de 2007

*Autor para correspondência (corresponding author)

E-mail: martinho@vet.ufmg.br

Apoio: $\mathrm{CNPq}$ 


\section{INTRODUÇÃO}

No Brasil, as dietas para codornas são formuladas com base nos requisitos nutricionais propostos pelo NRC (Nutrient..., 1994). Entretanto, essas exigências não são as mais apropriadas para as condições climáticas brasileiras, havendo necessidade do desenvolvimento de pesquisas que busquem determinar as exigências em nossas condições.

As fontes energéticas e protéicas das dietas têm sido os componentes de maior participação nos custos dessas dietas, devendo, portanto, estar em quantidades suficientes para suprir as necessidades visando o máximo desempenho das aves, sem onerar os custos de produção (Forbes e Shariatmandari, 1994, Oliveira et al., 2002b).O comprometimento do desempenho produtivo das codornas japonesas pode ser evidenciado em aves que consomem dietas cujos valores de energia metabolizável são diferentes de suas exigências (Oliveira et al., 2007).

O NRC (Nutrient..., 1994) recomenda para as fases inicial e de crescimento, níveis de $24 \%$ de proteína bruta (PB) e 2900kcal de energia metabolizável $(\mathrm{EM}) / \mathrm{kg}$ de dieta para codornas japonesas. Murakami et al. (1993), ao realizarem um experimento com codornas japonesas na fase de crescimento, observaram ótimo desempenho com níveis de $20 \%$ de $\mathrm{PB}$ e $3000 \mathrm{kcal}$ de $\mathrm{EM} / \mathrm{kg}$ de ração. Oliveira et al. (2002a) indicaram níveis de $24,7 \%$ de PB para o máximo crescimento em codornas japonesas criadas para corte. Essas exigências se referem às codornas japonesas, as quais apresentam maior aptidão para postura e pesos inferiores aos das codornas para corte (Corrêa et al., 2006).

Rajini e Narahari (1998) compararam o desempenho de codornas em crescimento, alimentadas com dietas com 24, 26 e $28 \%$ de proteína no período de uma a três semanas, e 18 , 20 e $22 \%$ no período de quatro a seis semanas e níveis de energia metabolizável de 2400, 2600 e $2800 \mathrm{kcal}$ de EM/kg em ambos os períodos. Os autores verificaram maior ganho de peso e melhor conversão alimentar no período de uma a três semanas com dietas com $28 \%$ de PB, independente do nível de energia. Para o período de quatro a seis semanas, observaram que o nível de $20 \%$ de PB promoveu melhores ganhos de peso e conversão alimentar independentes do nível energético.

Este trabalho teve o objetivo de estabelecer os níveis de proteína bruta e energia metabolizável para codornas de corte durante a fase de crescimento.

\section{MATERIAL E MÉTODOS}

Utilizaram-se 384 codornas européias de corte, de ambos os sexos, com sete dias de idade, durante cinco períodos experimentais de sete dias. O delineamento foi o inteiramente ao acaso com seis repetições de oito codornas por unidade experimental em esquema de parcelas subdivididas. Os oito tratamentos, constituídos da combinação de dois níveis de energia metabolizável $(2900$ e $3100 \mathrm{kcal}$ de EM/kg de dieta) e quatro níveis de proteína bruta $(22,24$, 26 e $28 \%$ de PB) foram colocados nas parcelas, enquanto os cinco períodos $(7-14 ; 15-21 ; 22-28$; 29-35; 36-42 dias de idade) constituíram as subparcelas.

As dietas experimentais foram formuladas, baseando-se nas informações de composições dos ingredientes apresentadas por Rostagno et al. (2000) e para atender as exigências nutricionais das codornas usaram-se as recomendações do NRC (Nutrient..., 1994), exceto para PB e EM. As dietas foram fornecidas à vontade. As composições percentual e calculada das dietas experimentais estão apresentadas na Tab. 1.

As variáveis analisadas foram: ganho de peso (GP), peso acumulado (PA), consumo de ração (CR) e conversão alimentar (CA) nos diferentes períodos experimentais.

Para o controle de o consumo alimentar, as rações de cada repetição dos tratamentos foram acondicionadas em baldes plásticos, devidamente identificados. Ao final de cada semana a sobra de ração do comedouro de cada parcela foi devolvida ao balde correspondente, pesada e, por diferença, determinaram-se o consumo semanal e o diário (g/ave). A conversão alimentar foi calculada por meio do consumo de ração dividido pelo ganho de peso na semana. 


\section{Corrêa et al.}

Tabela 1. Composição das dietas experimentais utilizadas para codornas de corte do $7^{\circ}$ ao $42^{\circ}$ dia de idade, de acordo com os tratamentos

\begin{tabular}{|c|c|c|c|c|c|c|c|c|}
\hline \multirow[t]{2}{*}{ Ingrediente $(\%)$} & \multicolumn{4}{|c|}{$\begin{array}{c}2900 \mathrm{kcal} \mathrm{EM} / \mathrm{kg} \\
\text { Proteína bruta }(\%)\end{array}$} & \multicolumn{4}{|c|}{$\begin{array}{c}3100 \mathrm{kcal} \mathrm{EM} / \mathrm{kg} \\
\text { Proteína bruta }(\%)\end{array}$} \\
\hline & 22 & 24 & 26 & 28 & 22 & 24 & 26 & 28 \\
\hline Milho & 53,60 & 47,08 & 40,56 & 34,03 & 53,44 & 46,91 & 40,39 & 33,87 \\
\hline Farelo de soja & 36,54 & 42,05 & 47,56 & 53,07 & 37,64 & 43,15 & 48,66 & 54,17 \\
\hline Farelo de trigo & 4,00 & 4,00 & 4,00 & 4,00 & 1,00 & 1,00 & 1,00 & 1,00 \\
\hline Óleo de soja & 2,60 & 3,66 & 4,73 & 5,80 & 4,64 & 5,71 & 6,78 & 7,84 \\
\hline Calcário & 1,11 & 1,08 & 1,06 & 1,04 & 1,09 & 1,06 & 1,04 & 1,02 \\
\hline Fosfato bicálcico & 0,95 & 0,92 & 0,90 & 0,86 & 0,99 & 0,96 & 0,93 & 0,90 \\
\hline Suplem. min. e vit. ${ }^{1}$ & 0,50 & 0,50 & 0,50 & 0,50 & 0,50 & 0,50 & 0,50 & 0,50 \\
\hline Sal comum & 0,27 & 0,27 & 0,26 & 0,25 & 0,27 & 0,27 & 0,26 & 0,26 \\
\hline DL- metionina & 0,09 & 0,14 & 0,18 & 0,23 & 0,10 & 0,15 & 0,19 & 0,24 \\
\hline L-treonina & 0,07 & 0,10 & 0,13 & 0,16 & 0,07 & 0,11 & 0,14 & 0,17 \\
\hline Inerte & 0,27 & 0,20 & 0,12 & 0,05 & 0,26 & 0,18 & 0,11 & 0,03 \\
\hline Total & 100,00 & 100,00 & 100,00 & 100,00 & 100,00 & 100,00 & 100,00 & 100,00 \\
\hline \multicolumn{9}{|l|}{ Composição calculada } \\
\hline Proteína bruta $(\%)$ & 22,00 & 24,00 & 26,00 & 28,00 & 22,00 & 24,00 & 26,00 & 28,00 \\
\hline En. metab. (kcal/kg) & 2900 & 2900 & 2900 & 2900 & 3100 & 3100 & 3100 & 3100 \\
\hline Cálcio $(\%)$ & 0,80 & 0,80 & 0,80 & 0,80 & 0,80 & 0,80 & 0,80 & 0,80 \\
\hline Fósf. disponível (\%) & 0,30 & 0,30 & 0,30 & 0,30 & 0,30 & 0,30 & 0,30 & 0,30 \\
\hline Met.+Cist. (\%) & 0,78 & 0,87 & 0,96 & 1,05 & 0,78 & 0,87 & 0,96 & 1,05 \\
\hline Metionina (\%) & 0,53 & 0,60 & 0,67 & 0,74 & 0,54 & 0,61 & 0,68 & 0,75 \\
\hline Lisina $(\%)$ & 1,17 & 1,31 & 1,45 & 1,59 & 1,19 & 1,32 & 1,46 & 1,60 \\
\hline Treonina $(\%)$ & 0,92 & 1,02 & 1,13 & 1,24 & 0,92 & 1,03 & 1,14 & 1,25 \\
\hline
\end{tabular}

${ }^{1}$ Composição/quilo: vit.A: $2.000 .000 \mathrm{UI}$; vit. $\mathrm{D}_{3}: 375.000 \mathrm{UI}$; vit.E: $3.750 \mathrm{mg}$; vit.k $\mathrm{k}_{3}: 500 \mathrm{mg}$; vit. $\mathrm{B}_{1}: 250 \mathrm{mg}$; vit. $\mathrm{B}_{2}: 750 \mathrm{mg}$; vit. $\mathrm{B}_{6}: 500 \mathrm{mg}$; vit $\mathrm{B}_{12}: 3.750 \mathrm{mcg}$; niacina: $6.250 \mathrm{mg}$; ac.pantotênico: $2.500 \mathrm{mg}$; biotina: $10 \mathrm{mg}$; ac.fólico: $125 \mathrm{mg}$; colina: $75.000 \mathrm{mg}$; metionina: $250.000 \mathrm{mg}$; selênio: $45 \mathrm{mg}$; iodo: $175 \mathrm{mg}$; ferro: $12.525 \mathrm{mg}$; cobre: $2.500 \mathrm{mg}$; manganês: $19.500 \mathrm{mg}$; zinco: $13.750 \mathrm{mg}$; avilamicina: $15.000 \mathrm{mg}$; narasin: $12.250 \mathrm{mg}$; B.H.T.: $500 \mathrm{mg}$; vit.C: $12.500 \mathrm{mg}$.

As análises estatísticas foram realizadas por meio do Programa SAEG (Sistema..., 2004). Os efeitos dos níveis de proteína e energia e suas interações foram estudados por meio de análise de variância e modelos de regressão linear e quadrática.

\section{RESULTADOS E DISCUSSÃO}

O ganho de peso das codornas (Tab. 2) apresentou efeito linear significativo dos níveis de proteína no $1^{\circ}$ período em ambos os níveis de energia, segundo as equações $\hat{Y}_{i}=32,82+0,60 \mathrm{x}_{\mathrm{i}}$,

$$
\begin{array}{cccccc}
\mathrm{R}^{2}=0,27 & (2900 & \mathrm{kcal} & \mathrm{de} & \mathrm{EM} / \mathrm{kg}) & \mathrm{e} \\
\hat{\mathrm{Y}}_{\mathrm{i}}= & 17,42+1,20 & \mathrm{x}_{\mathrm{i}}, & \mathrm{R}^{2}=0,68 & (3100 \mathrm{kcal} & \mathrm{de}
\end{array}
$$

$\mathrm{EM} / \mathrm{kg}$ ). Portanto, à medida que se aumentava $\mathrm{o}$ nível de PB da dieta, aumentava-se o ganho de peso, indicando a exigência de altos níveis de proteína na dieta das codornas nesta idade.

Oliveira et al. (2002b), ao trabalharem com níveis de 18 a $26 \%$ de proteína bruta, para codornas japonesas, observaram efeito linear crescente no ganho de peso nos períodos de 5-16 e 16-27 dias de idade, em função do nível protéico da dieta. 
Exigências de proteína bruta e energia...

Tabela 2. Médias das variáveis em relação aos níveis de energia, proteína e período, para codornas européias durante o crescimento

\begin{tabular}{|c|c|c|c|c|c|c|c|c|c|c|}
\hline \multicolumn{11}{|c|}{ Ganho de peso(g) } \\
\hline $\mathrm{EM}(\mathrm{kcal} / \mathrm{kg})$ & \multicolumn{3}{|c|}{2900} & \multicolumn{7}{|c|}{3100} \\
\hline Período\Proteína & 22 & 24 & 26 & 28 & Médias & 22 & 24 & 26 & 28 & Médias \\
\hline $1^{\circ}(7-14$ dias $)$ & 45,96 & 47,29 & 48,63 & 49,52 & 47,85 & 53,40 & 47,10 & 48,23 & 51,03 & 49,94 \\
\hline $2^{\circ}(15-21$ dias $)$ & 65,19 & 61,88 & 61,77 & 61,79 & 62,66 & 61,24 & 67,36 & 66,21 & 65,57 & 65,09 \\
\hline $3^{\circ}(22-28$ dias $)$ & 54,82 & 56,36 & 60,33 & 59,37 & 57,72 & 60,24 & 57,50 & 57,92 & 56,56 & 58,05 \\
\hline $4^{\circ}(29-35$ dias $)$ & 40,45 & 35,03 & 43,39 & 38,75 & 39,40 & 44,11 & 36,67 & 40,00 & 44,66 & 41,36 \\
\hline $5^{\circ}(36-42$ dias $)$ & 39,27 & 44,94 & 32,62 & 29,92 & 36,69 & 34,64 & 45,00 & 34,88 & 39,27 & 38,45 \\
\hline Médias & 49,14 & 49,10 & 49,35 & 47,87 & & 50,73 & 50,73 & 49,45 & 51,42 & \\
\hline \multicolumn{11}{|l|}{$\mathrm{CV}=10,43$} \\
\hline \multicolumn{11}{|c|}{ Peso acumulado (g) } \\
\hline $\mathrm{EM}(\mathrm{kcal} / \mathrm{kg})$ & \multicolumn{4}{|c|}{2900} & \multicolumn{6}{|c|}{3100} \\
\hline Período\Proteína & 22 & 24 & 26 & 28 & Médias & 22 & 24 & 26 & 28 & Médias \\
\hline $1^{\circ}(7-14$ dias $)$ & 73,20 & 74,58 & 75,94 & 76,75 & 75,12 & 70,61 & 74,31 & 75,46 & 78,24 & 74,65 \\
\hline $2^{\circ}(15-21$ dias $)$ & 138,39 & 139,43 & 137,71 & 138,54 & 138,52 & 131,84 & 141,67 & 141,67 & 143,81 & 139,75 \\
\hline $3^{\circ}(22-28$ dias $)$ & 193,21 & 195,80 & 198,03 & 197,92 & 196,24 & 192,08 & 199,17 & 199,58 & 200,38 & 197,80 \\
\hline $4^{\circ}(29-35$ dias $)$ & 236,50 & 230,83 & 241,43 & 236,67 & 236,36 & 236,19 & 235,83 & 239,17 & 245,03 & 239,05 \\
\hline $5^{\circ}(36-42$ dias $)$ & 275,77 & 275,77 & 274,05 & 258,67 & 271,06 & 270,83 & 280,83 & 274,05 & 282,64 & 277,09 \\
\hline Médias & 183,41 & 229,10 & 185,43 & 181,71 & & 180,31 & 165,76 & 185,99 & 190,02 & \\
\hline \multicolumn{11}{|l|}{$\mathrm{CV}=2,83$} \\
\hline \multicolumn{11}{|c|}{ Consumo de ração(g) } \\
\hline $\mathrm{EM}(\mathrm{kcal} / \mathrm{kg})$ & \multicolumn{4}{|c|}{2900} & \multicolumn{6}{|c|}{3100} \\
\hline Período \Proteína & 22 & 24 & 26 & 28 & Médias & 22 & 24 & 26 & 28 & Médias \\
\hline $1^{\circ}(7-14$ dias $)$ & 97,23 & 85,52 & 90,18 & 85,83 & 89,69 & 81,64 & 84,02 & 83,52 & 85,16 & 83,58 \\
\hline $2^{\circ}(15-21$ dias $)$ & 144,79 & 144,49 & 137,35 & 139,58 & 141,55 & 130,65 & 135,00 & 137,50 & 138,94 & 135,52 \\
\hline $3^{\circ}(22-28$ dias $)$ & 193,33 & 192,29 & 197,53 & 195,00 & 194,54 & 185,48 & 193,54 & 187,50 & 183,59 & 187,53 \\
\hline $4^{\circ}(29-35$ dias $)$ & 237,73 & 244,02 & 249,76 & 240,00 & 242,88 & 242,50 & 233,75 & 238,33 & 248,27 & 240,71 \\
\hline $5^{\circ}(36-42$ dias $)$ & 285,78 & 282,32 & 247,50 & 251,41 & 266,75 & 247,44 & 272,92 & 236,25 & 268,87 & 256,37 \\
\hline Médias & 191,77 & 189,73 & 184,46 & 182,36 & & 177,54 & 183,85 & 176,62 & 184,97 & \\
\hline \multicolumn{11}{|l|}{$\mathrm{CV}=7,61$} \\
\hline \multicolumn{11}{|c|}{ Conversão alimentar(g/g) } \\
\hline EM(kcal/kg) & \multicolumn{4}{|c|}{2900} & \multicolumn{6}{|c|}{3100} \\
\hline Período\Proteína & 22 & 24 & 26 & 28 & Médias & 22 & 24 & 26 & 28 & Médias \\
\hline $1^{\circ}(7-14$ dias $)$ & 2,12 & 1,80 & 1,85 & 1,73 & 1,87 & 1,88 & 1,78 & 1,73 & 1,67 & 1,76 \\
\hline $2^{\circ}(15-21$ dias $)$ & 2,24 & 2,34 & 2,23 & 2,27 & 2,27 & 2,14 & 1,99 & 2,08 & 2,12 & 2,08 \\
\hline $3^{\circ}(22-28$ dias $)$ & 3,53 & 3,42 & 3,28 & 3,30 & 3,38 & 2,96 & 3,38 & 3,26 & 3,26 & 3,21 \\
\hline $4^{\circ}(29-35$ dias $)$ & 6,05 & 7,02 & 5,82 & 6,27 & 6,29 & 5,50 & 6,52 & 5,97 & 5,61 & 5,90 \\
\hline $5^{\circ}$ (36-42 dias) & 6,89 & 6,44 & 7,66 & 8,61 & 7,40 & 7,32 & 6,18 & 7,22 & 6,91 & 6,91 \\
\hline Médias & 4,17 & 4,20 & 4,17 & 4,44 & & 3,96 & 3,97 & 4,05 & 3,91 & \\
\hline
\end{tabular}

Efeito quadrático do ganho de peso foi observado nos períodos seguintes:

$2^{\mathrm{o}}\left(\hat{Y}_{i}=211,36+21,69 \mathrm{x}_{\mathrm{i}}-0,42 \mathrm{x}_{\mathrm{i}}^{2}, \mathrm{R}^{2}=0,35\right)$,

$3^{\mathrm{o}}\left(\hat{Y}_{i}=60,93+8,67 \mathrm{x}_{\mathrm{i}}-0,15 \mathrm{x}_{\mathrm{i}}^{2}, \mathrm{R}^{2}=0,26\right)$,

$4^{\mathrm{o}}\left(\hat{Y}_{i}=503,93+37,56 \mathrm{x}_{\mathrm{i}}+0,76 \mathrm{x}_{\mathrm{i}}^{2}, \mathrm{R}^{2}=0,33\right)$, e

$5^{\mathrm{o}}\left(\hat{Y}_{i}=258,61+45,41 \mathrm{x}_{\mathrm{i}}-0,52 \mathrm{x}_{\mathrm{i}}^{2}, \mathrm{R}^{2}=0,34\right)$,

porém no $2^{\circ}$ e $4^{\circ}$, para o nível de $3100 \mathrm{kcal}$ de $\mathrm{EM} / \mathrm{kg}$ de dieta, com ponto de máxima estimado em $25,7 \%$ e $24,8 \%$ de $\mathrm{PB}$, respectivamente, e no $3^{\circ}$ e $5^{\circ}$, para o nível de $2900 \mathrm{kcal}$ de $\mathrm{EM} / \mathrm{kg}$ de dieta, com seus pontos de máxima estimado em $27,9 \%$ e $23,1 \%$ de $\mathrm{PB}$, respectivamente. Estes resultados demonstram diminuição das exigências de $\mathrm{PB}$ nesses períodos em relação ao primeiro.

Shim e Vohra (1984) estimaram que na fase inicial (1 aos 14 dias de idade), o requisito em proteína para codornas japonesas para o máximo desempenho é alto ( 28 a $32 \%$ de PB), sendo que o crescimento diferenciado entre dietas com níveis mais altos e mais baixos desaparece após a terceira semana de idade em função do seu ganho compensatório. Os autores verificaram que o nível protéico poderia ser reduzido para $20 \%$ até a sexta semana de idade. Resultados semelhantes foram encontrados por Rajini e Narahari (1998) que observaram melhor ganho de peso no período de zero a três semanas com dietas com 
$28 \%$ de $\mathrm{PB}$, independente do nível energético e de quatro a seis semanas e observaram que níveis de $20 \%$ de PB foram suficientes para promover os melhores ganhos de peso em codornas japonesas.

Brandão et al. (1991) determinaram o nível de $24 \%$ de $\mathrm{PB}$ e $2200 \mathrm{kcal}$ de $\mathrm{EM} / \mathrm{kg}$ de ração, como sendo o mais adequado para codornas em crescimento e Murakami et al. (1993), ao estudarem níveis de 2800 e $3000 \mathrm{kcal}$ de $\mathrm{EM} / \mathrm{kg}$ de dieta com 20, 22, 24 e 26\% PB para codornas japonesas, verificaram que os níveis protéicos e energéticos para o máximo desempenho foram de $20 \%$ de $\mathrm{PB}$ e $3000 \mathrm{kcal}$ de $\mathrm{EM} / \mathrm{kg}$ de dieta.

Entretanto, Begin (1968) não verificou diferença em codornas com duas semanas de idade alimentadas com dois níveis de energia (3380 e $2180 \mathrm{kcal}$ de EM/kg/dieta). Oliveira et al. (2002a) encontraram para codornas japonesas machas criadas para produção de carne, nível de $24 \%$ de PB para a idade de cinco a 16 dias, $22 \%$ para 16 27 dias e $18 \%$ para $27-38$ dias. Enquanto Oliveira et al. (2002b) verificaram decréscimo no ganho de peso no período de 27-38 dias de idade, pois codornas alimentadas com dietas com $18 \%$ de proteína bruta tiveram maior ganho de peso.

O peso acumulado (Tab. 2) apresentou efeito linear em ambos os níveis de energia, no $1^{\circ}$ período $\left(\hat{Y}_{i}=60,14+0,60 \mathrm{x}_{\mathrm{i}}, \mathrm{R}^{2}=0,27(2900 \mathrm{kcal}\right.$ de $\mathrm{EM} / \mathrm{kg})$ e $\hat{Y}_{i}=44,60+1,20 \quad \mathrm{x}_{\mathrm{i}}, \mathrm{R}^{2}=0,69$ (3100kcal de $\mathrm{EM} / \mathrm{kg})$ ), conseqüência da alta exigência em proteína na fase inicial de crescimento, independente do nível energético, e efeito quadrático no $2^{\circ}\left(\hat{Y}_{i}=202,54-25,78\right.$ $\left.\mathrm{x}_{\mathrm{i}}+0,48 \mathrm{x}_{\mathrm{i}}^{2}, \mathrm{R}^{2}=0,61\right), 3^{\mathrm{o}}\left(\hat{Y}_{i}=77,56+20,92 \mathrm{x}_{\mathrm{i}}-\right.$ $\left.0,39 \mathrm{x}_{\mathrm{i}}^{2}, \mathrm{R}^{2}=0,25\right), 4^{\mathrm{o}}\left(\hat{Y}_{i}=442,94-17,96 \mathrm{x}_{\mathrm{i}}+\right.$ $\left.0,39 \mathrm{x}_{\mathrm{i}}^{2}, \mathrm{R}^{2}=0,41\right)$ e $5^{\mathrm{o}}\left(\hat{Y}_{i}=258,61+45,41 \mathrm{x}_{\mathrm{i}}-\right.$ $\left.0,96 \mathrm{x}_{\mathrm{i}}^{2}, \mathrm{R}^{2}=0,31\right)$ nos níveis de $3100 \mathrm{kcal} \mathrm{EM} / \mathrm{kg}$ de dieta para o $2^{\circ}, 3^{\circ}$ e $4^{\circ}$ períodos, e de $2900 \mathrm{kcal}$ de $\mathrm{EM} / \mathrm{kg}$ para o $5^{\circ}$ período, com pontos de máxima estimados no $2^{\circ}, 3^{\circ}, 4^{\circ}$ e $5^{\circ}$ período de $26,9 \%, \quad 26,6 \%, 22,5 \%$ e $23,6 \%$ de $P B$, respectivamente. Portanto, observa-se também diminuição das exigências em proteína e energia com o aumento da idade das codornas, com exceção do quinto período, quando houve aumento da exigência em proteína em relação ao período anterior, demonstrando que após a primeira semana há diminuição significativa nos níveis de proteína e energia exigidos pelas codornas em crescimento.

Estes dados são semelhantes aos apresentados por Hyánková et al. (1997) que, ao pesquisarem níveis de 19,5 a $26 \%$ de $\mathrm{PB}$ em diferentes linhagens de codornas japonesas para carne, verificaram exigência de níveis mais altos para a fase inicial (1 a 14 dias de idade), e na fase posterior (15 a 28 dias de idade), níveis mais baixos proporcionaram melhor desempenho (peso) das aves. Também Roush et al. (1979) verificaram, para codornas japonesas, que os níveis protéicos e energéticos mais adequados para obtenção do máximo crescimento às duas semanas de idade foram de $30 \%$ de PB e $11,2 \mathrm{Mj}$ de EM/kg de dieta. Fridrich et al. (2005) trabalharam com níveis de proteína bruta que variavam de 18 a $26 \%$, para codornas de corte, não verificaram efeito da proteína no peso corporal nos períodos de 18 a 28 e de 28 a 42 dias de idade e no ganho de peso no período de 18 a 28 dias de idade.

Sakuray (1981), Shrivastav et al. (1993), Oliveira et al. (2002a), Pinto et al. (2002) e Corrêa et al. (2005) não verificaram diferença no ganho de peso em codornas com o aumento do nível energético.

O consumo de dieta apresentou efeito quadrático no $1^{\circ}$ período $\left(\hat{Y}_{i}=411,67-24,46 \mathrm{x}_{\mathrm{i}}+0,46 \mathrm{x}_{\mathrm{i}}{ }^{2}\right.$, $\mathrm{R}^{2}=0,27$ ), cujo ponto de máximo encontrou-se em $26,6 \%$, e efeito linear no $2^{\circ} \quad\left(\hat{Y}_{i}=\right.$ $\left.101,34+1,37 \mathrm{x}_{\mathrm{i}}, \mathrm{R}^{2}=0,18\right)$ e $5^{\mathrm{o}}\left(\hat{Y}_{i}=439,15-\right.$ $\left.6,89 \mathrm{x}_{\mathrm{i}}, \mathrm{R}^{2}=0,29\right)$ períodos com níveis de energia de $2900 \mathrm{kcal}$ de $\mathrm{EM} / \mathrm{kg}$ no $1^{\mathrm{o}}$ e $5^{\circ}$ períodos e $3100 \mathrm{kcal}$ de $\mathrm{EM} / \mathrm{kg}$ no $2^{\circ}$ período. Nos demais períodos não foram observadas diferenças significativas. Farrel et al. (1982) indicam ingestão decrescente de energia até três semanas de idade, permanecendo constante após este período, o que também foi encontrado por Yamane (1979), Sakuray (1981), Murakami (1993) e Pinto et al. (2002), os quais observaram redução significativa do consumo de ração com o aumento de níveis de energia da dieta. Estes resultados, mais uma vez, indicam que as aves ajustam o consumo pelo nível energético da 
dieta, ou seja, as codornas que consomem dietas com menor teor calórico tendem a compensar o insuficiente consumo energético, ingerindo maior quantidade de alimento, a fim de manterem estáveis suas funções fisiológicas e assim confirmando a existência de um mecanismo regulador do consumo.

Ao estudar o efeito da proteína, Pinto et al. (2002) encontraram aumento no consumo de ração até o nível de $21,8 \%$ de $\mathrm{PB}$. Arscott et al. (1981) também verificaram aumento no consumo com o aumento da proteína. Contudo, Murakami (1993) não observou efeito significativo dos níveis protéicos de 20 a $26 \%$ sobre o consumo de alimento em codornas japonesas. Fridrich et al. (2005) não verificaram efeito significativo sobre o consumo alimentar durante os períodos de 1828 e $28-42$ dias de idade, quando variaram os níveis protéicos de 18 a $26 \%$.

Observou-se efeito linear dos níveis de proteína no $1^{\circ}$ período sobre a conversão alimentar, segundo a equação $\hat{Y}_{i}=2,94-0,04 \mathrm{x}_{\mathrm{i}}, \mathrm{R}^{2}=0,29$; nos demais períodos não foram observados diferenças significativas. Oliveira et al. (2002) observaram que a conversão alimentar melhorou com o aumento de níveis de energia no período de 38-45 dias de idade de codornas japonesas, no entanto, não observaram diferença significativa nos demais períodos, enquanto que Murakami et al. (1993) observaram melhor conversão alimentar em codornas japonesas com níveis de $2800 \mathrm{kcal} \mathrm{EM} / \mathrm{kg}$ de dieta, comparadas às aves que receberam $3000 \mathrm{kcal}$ de $\mathrm{EM} / \mathrm{kg}$ de dieta no período de 1 a 42 dias de idade. Oliveira et al. (2002b) verificaram, entre 27 e 38 dias de idade, efeito linear positivo dos níveis de proteína bruta da dieta, pois nesse período, codornas alimentadas com $18 \%$ de proteína bruta tiveram melhor conversão alimentar, enquanto entre $38 \mathrm{e}$ 49 dias de idade, a conversão alimentar foi menor quando alimentadas com dietas com $21,96 \%$ de proteína bruta. A conversão alimentar foi melhor com dietas com 3200kcal de EM/kg, nesse período.

\section{CONCLUSÕES}

Maiores ganhos de peso foram estimados nos níveis de $28 \%$ de $\mathrm{PB}$ no $1^{\circ}$ período, $25,71 \%$ de $\mathrm{PB}$ e $3100 \mathrm{kcal} \mathrm{EM} / \mathrm{kg}$ no $2^{\circ}$ período, $27,86 \%$ de
PB e $2900 \mathrm{kcal} \mathrm{EM} / \mathrm{kg}$ no $3^{\circ}$ período, $24,84 \%$ de $\mathrm{PB}$ e $3100 \mathrm{kcal}$ de EM no $4^{\circ}$ período e $23,07 \%$ de $\mathrm{PB}$ e $2900 \mathrm{kcal} \mathrm{EM} / \mathrm{kg}$ no $5^{\circ}$ período para codornas de corte durante o crescimento.

\section{REFERÊNCIAS BIBLIOGRÁFICAS}

ARSCOTT, G.H.; PIERSON GOEGER, M. Protein needs for laying Japonese quail as influenced by protein level and amino acid suplementation. Nutr. Rep. Int., v.24, p.12871295, 1981.

BEGIN, J.J. A Comparison of the ability of the japonese quail and light breed chicken to metabolize and utilize energy. Poult. Sci., v.47, p.1278-1281, 1968.

BRANDÃO, S.S.; REIS, J.C.; SANTOS, M.V.F. Efeito dos níveis de energia e proteína sobre o peso corporal de codornas (Coturnix coturnix japonica) das linhagens branca e pintada, na fase de crescimento. In: REUNIÃO ANNUAL DA SOCIEDADE BRASILEIRA DE ZOOTECNIA, 28, 1991, João Pessoa, PB. Anais... João Pessoa: SBZ, 1991. p.350.

CORRÊA, G.S.S.; SILVA, M.A.; FONTES, D.O. et al. Efeito de diferentes níveis de proteína e energia sobre o rendimento de carcaça de codornas européias. Arq. Bras. Med. Vet. Zootec., v.57, p.266-271, 2005.

CORRÊA, G.S.S.; SILVA, M.A.; CORRÊA, A.B. et al. Exigência de metionina + cistina total para codornas de corte em crescimento. Arq. Bras. Med. Vet. Zootec., v.58, p.414-420, 2006.

FARREL, D.J.; ATMAMIHARRDJA, S.I.; PYM, R.A.E. Calorimetric measurements of the energy and nitrogen metabolism of Japanese quail. Br. Poult. Sci., v.23, p.375-382, 1982.

FORBES, J.M.; SHARIATMANDARI, F. Diet selection for protein by poultry. World's Poult. Sci., v.50, p.7-23, 1994.

FRIDRICH, A.B.; VALENTE, B.D.; FELIPESILVA, A.S. et al. Exigência de proteína bruta para codornas européias no período de crescimento. Arq. Bras. Med. Vet. Zootec., v.57, p.261-265, 2005.

HYÁNKOVÁ, L.; DEDKOVÁ, L.; KNIZETVÁ, $H$. et al. Responses in growth, food intake and food conversion efficiency to different dietary 


\section{Corrêa et al.}

protein concentrations in meat-type lines of japonese quail. Br. Poult. Sci., v.38, p.564-570, 1997.

MURAKAMI, A.E.; MORAES, V.M.B.; ARIKI, J. et al. Níveis de proteína e energia em rações para codornas japonesas (Coturnix coturnix japonica) em crescimento. Rev. Bras. Zootec., v.4, p.534-540, 1993.

NUTRIENT Requirements of poultry. 9.ed. Washington: National Academy of Sciences, 1994. p.44-45.

OLIVEIRA, N.T.E.; FONSECA, J.B.; SOARES, R.T.N. et al. Determinação da energia metabolizável de diferentes alimentos testados em codornas japonesas fêmeas. Arq. Bras. Med. Vet. Zootec., v.59, p.210-217, 2007.

OLIVEIRA, N. T. E.; SILVA, M. A.; SOARES, R. T. N. et al. Exigências de energia e proteína para codornas japonesas machos criadas para a produção de carne. Rev. Bras. Zootec., v.31, p. 675-686, 2002a.

OLIVEIRA, N.T.E.; SILVA, M.A.; SOARES, R.T.N. et al. Exigências de proteína bruta e energia metabolizável para codornas japonesas machos criadas para a produção de carne. Arq. Bras. Med. Vet. Zootec., v.54, p.196-203, 2002 b.

PINTO, R.; FERREIRA, A.S.; ALBINO, L.F.T. et al. Níveis de proteína e energia para codornas Japonesas em Postura. Rev. Bras. Zootec., v.31, p.1761-1770, 2002.
RAJINI, R.A.; NARAHARI, D. Dietary energy and protein requirements of growing Japanese quails in the tropics. Indian J. Anim. Sci., v.68, p.1082-1086, 1998.

ROSTAGNO, H.S.; ALBINO, L.F.T.; DONZELE, J.L. et al. Composição de Alimentos $e$ exigências nutricionais de aves e suinos: Tabelas Brasileiras. Viçosa, MG. Universidade Federal de Viçosa, 2000. 141p.

ROUSH, W.B.; PETERSEN, R.G.; ARSCOTT, G.H. Na application of response surface methodology to research in poultry nutrition. Poult. Sci., v.58, p.1504-1513, 1979.

SAKURAI, H. Influence of dietary levels of protein and energy on nitrogen and energy balance for egg production of Japanese quail. Jpn.. Poult. Sci., v.18, p.185-192, 1981.

SHIM, K.F.; VORHA, P. A review of the nutrition of Japonese quail. Worlds Poult. Sci. J., v.40, p.261-274, 1984.

SHRIVASTAV, A.K.; RAJU, M.V.L.N.; JOHN, T.S. Effect of varied dietary protein on certain production traits in breeding Japanese quail. Ind. J. Poult. Sci., v.28, p.20-25, 1993.

SISTEMA de análises estatísticas e genéticas SAEG, Versão 9.0. Viçosa, MG: UFV, 2004.

YAMANE, T.; ONO, K.; TANAKA T. Energy requeriment of laying Japonese quail. Br. Poult. Sci., v.20, p.379-383, 1979. 